\title{
Rast i rodnost sorti lijeske na podlozi Corylus colurna i vlastitom korijenu u ekološkim uvjetima Istre
}

\author{
Growth and yield of hazelnut varieties on the rootstock \\ Corylus colurna and their own root in ecological conditions of Istria
}

\section{Miljković}

\section{SAŽETAK}

Istraživanje vegetativne razvijenosti i rodnosti sorti lijeske provedena su u dva pokusna voćnjaka u Istri. U prvom pokusnom voćnjaku istraživanja su obuhvatila sorte: Fertile de Coutard, Cosford, Gunslebert, Istarski duguljasti, Merveille de Bollwiller, Magonca i Tonda Gentile Romana na podlozi Corylus colurna, a uzgojene u obliku stabla s krošnjom u obliku vaze. Razmak sadnje je 5 x 5 m (400 stabala/ha). Sve su sorte postigle dobru vegetativnu razvijenost na kraju 6. vegetacije. Veću bujnost od ostalih 6 sorti postigla je sorta Fertile de Coutard. Razlika je visokosignifikantna. Podjednaku vegetativnu razvijenost postiglo je ostalih 6 sorti. Najveći prirod postigla je sorta Cosford, a slijede je Fertile de Coutard, Istarski duguljasti, Tonda Romana, Magonca i Gunslebert, a najmanji sorta Merveille de Bollwiller. U drugom pokusnom voćnjaku istraživana je vegetativna razvijenost i rodnost sorti: Istarski duguljasti, Tonda Gentile Romana i Fertile de Coutard uzgojene na vlastitom korijenu u obliku grmolike vaze s razmakom $4,5 \times 4,5 \mathrm{~m}$ (493 stabla/ha). Na kraju 6 . vegetacije sve su sorte postigle dobru razvijenost. Veću bujnost od sorte Istarski duguljasti postigle su sorte Fertile de Coutard i Tonda Gentile Romana. Podjednak prirod utvrđen je za sorte na vlastitom korijenu. Usporedbom vegetativne razvijenosti stabala na vlastitom korijenu i podlozi Corylus colurna utvrđeno je da su sve tri sorte na podlozi Corylus colurna postigle znatno veću bujnost. Usporedbom rodnosti sorti Istarski duguljasti, Tonda Romana i Fertile de Coutard na vlastitom korijenu i istih sorti na podlozi Corylus colurna ustanovljeno je da su sve 3 sorte dale znatno veći prirod na podlozi Corylus colurna. Istraživanja su obuhvatila utjecaj podloge na kemijski sastav lišća sorti: Fertile de Coutard, Istarski duguljasti i Tonda Gentile Romana. Provedena je analiza uzroka prijevremenog opadanja plodova.

Ključne riječi: lijeska, sorte, podloga, rast, rodnost, kemijska analiza 


\begin{abstract}
Research on the vegetative growth and yield of the varieties of hazelnut was carried out in two experimental orchards in Istria. In the first experimental orchard, the research included the varieties: Fertile de Coutard, Cosford, Gunslebert, Istarski duguljasti, Merveille de Bollwiller, Magonca and Tonda Gentile Romana on the rootstock Corylus colurna. Planting distances were $5 \times 5 \mathrm{~m}$ (400 trees / ha) with the training form of open vase. All varieties achieved good vegetative development at the end of the $6^{\text {th }}$ vegetation. Greater development than the other 6 varieties. The Fertile de Coutard variety achieved. The difference was highly significant. Equal vegetative development was achieved by the other 6 varieties. The Cosford variety had to highest yield, followed by Fertile de Coutard, Istarski duguljasti, Tonda Gentile Romana, Magonca and Gunslebert, and the smallest variety by Merveille de Bollwiller. In the second experimental orchard, the vegetative development and yield of the varieties: Istarski duguljasti, Tonda Gentile Romana and Fertile de Coutard were investigated grown on their own roots in the form of bushy vases with a distance of $4.5 \times 4.5 \mathrm{~m}$ (493 trees / ha). At the end of the $6^{\text {th }}$ vegetation all varieties achieved good development. Fertile de Coutard and Tonda Gentile Romana had grown to a greater extent than the Istrian duguljasti. Equal yield was obtained by varieties on their own root. By comparing the vegetative development of trees on their own roots and on the rootstock of Corylus colurna it was found that all three varieties on the rootstock of Corylus colurna achieved significantly greater vegetative development. By comparing the genotype of the Istarski duguljasti, Tonda Romana and Fertile de Coutard on their own roots and the same varieties on the rootstock Corylus colurna, it was found that all 3 varieties yielded much better on the substrate of Corylus colurna. The research included the influence of the rootstock on the chemical composition of the leaves of the varieties: Fertile de Coutard, Istarski duguljasti and Tonda Gentile Romana. An analysis of the cause of premature dropping of fruits was carried out.
\end{abstract}

Key words: hazelnut, variety, rootstock, growth, yield, leaves, chemical analysis

\title{
UVOD
}

Uzgoj lijeske i proizvodnja lješnjaka doživljava pravi preporod. Iz godine u godinu lijeska se uzgaja na sve većim površinama. Proizvodnja lješnjaka, uz uvođenje novih tehnologija, po jedinici površine osjetno se povećava. Ranije su u Istri, kao našem glavnom i tradicijskom području, bile zastupljene dvije autohtone hrvatske sorte Istarski duguljasti i Istarski okruglasti. Uz ove dvije sorte bilo je i više tipova iz populacije, koji su osiguravali oprašivanje i oplodnju. Osamdesetih godina prošlog stoljeća pokazala se potreba za 
proširenjem sortimenta i uvođenje u proizvodnju novih stranih sorti. Tako je podignut novi intenzivni lijesik sa više novih stranih sorti na objektu Garbinovica u sastavu Agrolagune u Poreču. U to je vrijeme odlučeno da se u Slavoniji podigne velika plantaža lijeske. Godine 1981. napisao sam Izvedbeni projekt za podizanje 200 ha lijeske na objektu „Bukvik“ u sastavu P. D. Orahovica. Bila je to naša prva velika plantaža, koja je po veličini i danas najveća u Europi. Tada sam osjetio teškoće u radu, jer nismo imali gotovo nikakvog iskustva sa stranim sortama u našim ekološkim uvjetima. Kako sam tada radio projekt za podizanje većeg nasada lijeske na objektu „Kršin“ na lokalitetu Boško Monte u sastavu P. I. K. Umag, to sam na tom objektu podigao i prve pokusane nasade s više sorti lijeske, uzgojenih na vlastitom korijenu i podlozi Corylus colurna. To su bila prva nastojanja na proširenju znanja o biološkim i gospodarskim svojstvima introduciranih stranih sorti. Osim toga, u to vrijeme provođena su i istraživanja $u$ bogatoj populaciji tipova lijeske $u$ proizvodnim voćnjacima na zapadnoj obali Istre, pa je izdvojeno nekoliko tipova. Ta bi istraživanja trebalo nastaviti i proširiti. Selekcijskim radom dobiven je, u posljednje vrijeme, velik broj vrlo kvalitetnih novih sorti, koje bi trebalo uvesti i istražiti u našim ekološkim uvjetima. Za brz razvoj i unapređenje proizvodnje lješnjaka potrebno je slijediti dostignuća u znanosti i proizvodnoj praksi doma i u svijetu. Voćarska znanost u Hrvatskoj ne može se razvijati bez kolekcijskih i pokusnih voćnjaka, jer odvajati znanost od stvarnosti, a ne rješavati probleme za potrebe proizvodnje, nema opravdanja. Bez identiteta kritičnosti u znanosti, znanost postaje „lar pour lar“. Stiče se dojam da je znanost ušla u rutinsko ponavljanje poznatog bez obzira dali će naći primjenu u praksi. Voćarska znanost je primijenjena interdisciplinarna, pa treba rješavati probleme koji će naći praktičnu primjenu.

\section{OBJEKT ISTRAŽIVANJA I METODE RADA}

Istraživanja su obavljena u dva pokusna voćnjaka, koji su podignuti 1984. godine.

U prvom voćnjaku posađene su sorte: Istarski duguljasti, Fertile de Coutard, Cosford, Gunslebert, Merveille de Bollwiller, Tonda Gentile Romana i Magonca cijepljene na podlozi Corylus colurna. Sorte su posađene na razmak 5 x 5 m, a uzgojene kao stablašice s krošnjom u obliku popravljene vaze (slika 1). Pokus je postavljen po metodi randomiziranog bloka u 4 ponavljanja, a $\mathrm{u}$ svakom bloku je zastupljeno po 4 stabla, taka da je svaka sorta bila zastupljena sa po 16 stabala. 


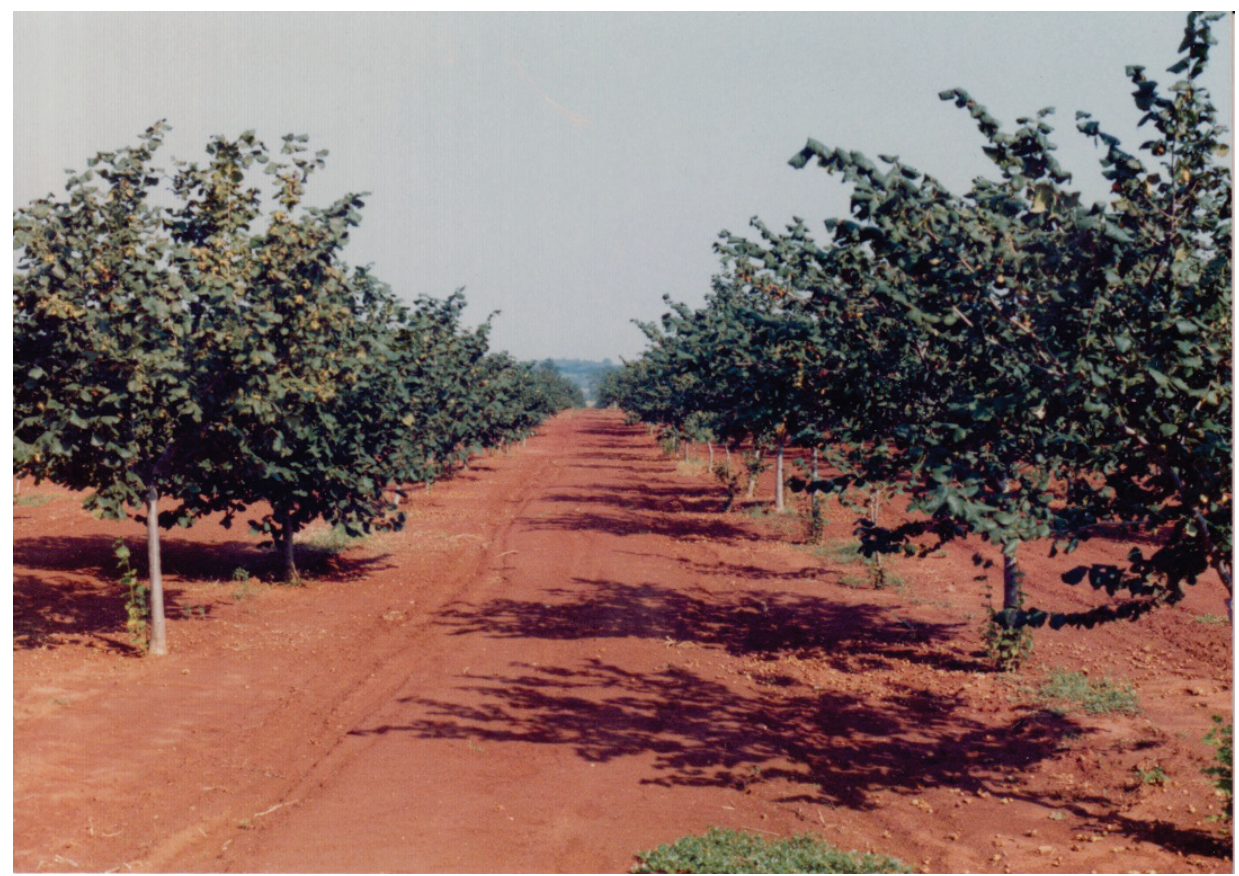

Slika 1. Pokusni voćnjak

\section{Figure 1 Experimental orchard}

U drugom pokusnom voćnjaku istraživane su sorte: Istarski duguljasti, Tonda Gentile Romana i Fertile de Coutard. Lijeske su posađene na razmak 4,5 $\mathrm{x} 4,5 \mathrm{~m}$, a uzgajane na vlastitom korijenu sa stablima u obliku grmolike vaze $\mathrm{s}$ deblom visine $40 \mathrm{~cm}$. Pokus je postavljen po metodi randomiziranog bloka u 4 repeticije, a u svakom je bloku pojedina sorta bila zastupljena sa po 4 stabla. U oba voćnjaka istraživanja su obuhvatila vegetativnu razvijenost i rodnost. Vegetativna razvijenost, visine i širine krošnje utvrđena je izmjerama promjera debla na visini od $30 \mathrm{~cm}$. Prirod je utvrđen po stablu i preračunat na 1 ha. Istraživanja su obuhvatila kontrolu opskrbljenosti elementima u sorti uzgojenih na vlastitom korijenu i podlozi Corylus colurna analizom kemijskog sastava lišća, odnosno folijarnom dijagnozom. U proizvodnim voćnjacima istraživani su uzroci prijevremenog opadanja plodova. Rezultati istraživanja obrađeni su varijaciono statistički analizom varijance. 


\section{REZULTATI ISTRAŽIVANJA}

Rezultati istraživanja vegetativne razvijenosti sorti lijeske na podlozi Corylus colurna na kraju 6. vegetacije izneseni su u tablici 1.

Tablica 1. Vegetativna razvijenost sorti lijeske na podlozi Corylus colurna na kraju 6. vegetacije

Table 1 Vegetative growth of hazelnut varieties on rootstock Corylus colurna at the end of the $6^{\text {th }}$ vegetation

\begin{tabular}{|c|c|c|c|}
\hline $\begin{array}{c}\text { Sorta } \\
\text { Variety }\end{array}$ & $\begin{array}{c}\text { Promjer debla }-\mathrm{cm} \\
\text { Trunk diameter }-\mathrm{cm}\end{array}$ & $\begin{array}{c}\text { Visina stabla }-\mathrm{cm} \\
\text { Height of Tree }-\mathrm{cm}\end{array}$ & $\begin{array}{c}\text { Širina krošnje - cm } \\
\text { Spread of Crown - cm }\end{array}$ \\
\hline Fertile de Coutard & 16,34 & 362 & 534 \\
\hline Cosford & 9,88 & 346 & 342 \\
\hline Merveille de Bollwiller & 9,78 & 266 & 300 \\
\hline Gunslebert & 10,90 & 344 & 316 \\
\hline Magonca & 10,12 & 352 & 356 \\
\hline Tonda Gentile Romana & 10,74 & 310 & 248 \\
\hline Istarski duguljasti & 10,32 & 248 & 298 \\
\hline L. S. D. P $=5 \%$ & 1,95 & 0,28 & 0,55 \\
\hline L. S. D. P $=1 \%$ & 2,62 & 0,38 & 0,75 \\
\hline
\end{tabular}

$\mathrm{Na}$ osnovi istraživanja ustanovljeno je da najveći promjer debla, visinu stabla i širinu krošnje ima sorta Fertile de Coutard (Barcelona). Utvrđena je signifikantna razlika za promjer debla između sorte Fertile de Coutard i sorti: Cosford, Gunslebert, Merveille se Bollwiller, Tonda Gentile Romana i Istarski duguljasti. Utvrđena je signifikantna razlika za visinu stabla između Sorte Fertile de Coutard i ostalih 6 sorti. Podjednaku visinu stabla razvile su sorte: Cosford, Gunslebert i Magonca. Utvrđena je statistički opravdana razlika za visinu stabla između spomenute 3 sorte i sorti: Merveille de Bollwiller, Tonda Gentile Romana i Istarski duguljasti. Najširu krošnju razvija sorta Fertile de Coutard, podjednako široke krošnje imaju sorte: Cosford, Gunslebert, Merveille de Bollwiller, Magonca i Istarski duguljasti, a najmanju Tonda Gentile Romana. Iz toga proizlazi zaključak da se sorte ovisno o bujnosti sade na različit razmak u voćnjaku.

$\mathrm{U}$ tablici 2 izneseni su podatci o prirodu $\mathrm{u} \mathrm{kg} / \mathrm{stablo}$ i na 1 ha. 
Tablica 2. Rodnost sorti lijeske na podlozi Corylus colurna u 6. vegetaciji

Table 2 Yield of hazelnut varieties on rootstock Corylus colurna at the end of the $6^{\text {th }}$ vegetation

\begin{tabular}{|l|c|c|}
\hline \multicolumn{1}{|c|}{ Sorta - Variety } & kg/stablo (tree) & kg/ha \\
\hline Fertile de Coutard & $4,86 \mathrm{~b}$ & 1944 \\
\hline Cosford & $5,20 \mathrm{a}$ & 2080 \\
\hline Gunslebert & $4,12 \mathrm{c}$ & 1648 \\
\hline Merveille de Bollwiller & $3,90 \mathrm{~d}$ & 1560 \\
\hline Magonca & $4,25 \mathrm{c}$ & 1700 \\
\hline Tonda Gentile Romana & $4,30 \mathrm{c}$ & 1720 \\
\hline Istarski duguljasti & $4,35 \mathrm{c}$ & 1740 \\
\hline
\end{tabular}

Srednje vrijednosti označene istim slovom nisu međusobno signifikantne.

Means followed by the same letter are not significant.

Najveći prirod po stablu postigle su sorte Cosford (2.080 kg/ha), i Fertile de Coutard (1.944 kg/ha), podjednak sorte: Istarski duguljasti, Tonda Gentile Romana, Magonca i Gunslebert, a najmanji Merveille de Bollwiller (3,90 kg). Utvrđena je statistički opravdana razlika za visinu priroda između dvije sorte, odnosno Cosford i Fertile de Coutard i sorta Istarski duguljasti, Tonda Gentile Romana, Magonca i Gunslebert. Najniži prirod postigla je sorta Merveille de Bollwiller. U količini priroda sorte Merveille de Bollwiller i ostalih 6 sorti razlika je opravdana.

U tablici 3 predočeni su rezultati istraživanja vegetativne razvijenosti sorti: Fertile de Coutard, Tonda Gentile Romana i Istarski duguljasti, koje su uzgojene na vlastitom korijenu.

Tablica 3. Vegetativna razvijenost stabala lijeske na vlastitom korijenu na kraju 6. vegetacije

Table 3 Vegetative growth of hazelnut varieties on their own root at the end of the $6^{\text {th }}$ vegetation

\begin{tabular}{|l|c|c|c|}
\hline \multicolumn{1}{|c|}{$\begin{array}{c}\text { Sorta } \\
\text { Variety }\end{array}$} & $\begin{array}{c}\text { Promjer debla }-\mathrm{cm} \\
\text { Trunk diameter }\end{array}$ & $\begin{array}{c}\text { Visina stabla }-\mathrm{cm} \\
\text { Height of Tree }\end{array}$ & $\begin{array}{c}\text { Sirina krošnje }-\mathrm{cm} \\
\text { Spread of Crown }\end{array}$ \\
\hline Fertile de Coutard & $8,66 \mathrm{a}$ & $298 \mathrm{~b}$ & $233 \mathrm{a}$ \\
\hline Tonda Gentile Romana & $8,10 \mathrm{~b}$ & $320 \mathrm{a}$ & $231 \mathrm{a}$ \\
\hline Istarski duguljasti & $7,20 \mathrm{c}$ & $248 \mathrm{c}$ & $229 \mathrm{a}$ \\
\hline
\end{tabular}

Srednje vrijednosti označene istim slovima nisu međusobno signifikantne.

Means followed by the same letter are not significant. 
U tablici vidimo da je najveću bujnost i na vlastitom korijenu postigla sorta Fertile de Coutard, a najmanju sorta Istarski duguljasti. Razlika u bujnosti između istraživanih sorti je statistički opravdana. Uz razmak 4,5 x 4,5 m istraživane sorte su popunile gustoću sklopa i razvile podjednako široke krošnje.

U tablici 4 izneseni su podatci o rodnosti sorti uzgajanih na vlastitom korijenu.

Tablica 4. Rodnost sorti lijeske na vlastitom korijenu u 6. vegetaciji

Table 4 Yield of hazelnut varieties on their own root at the end of the $6^{\text {th }}$ vegetation

\begin{tabular}{|l|c|c|}
\hline $\begin{array}{c}\text { Sorta } \\
\text { Variety }\end{array}$ & $\begin{array}{c}\text { Prirod kg/stablo } \\
\text { Yield }-\mathrm{kg} / \text { tree }\end{array}$ & $\begin{array}{c}\text { Prirod kg/ha } \\
\text { Yield kg/ha }\end{array}$ \\
\hline Fertile de Coutard & 3,30 & 1.630 \\
\hline Tonda Gentile Romana & 3,15 & 1.560 \\
\hline Istarski duguljasti & 3,15 & 1.560 \\
\hline L. S. D. P $=5 \%$ & N. S. & \\
\hline
\end{tabular}

U tablici vidimo da su istraživane sorte postigle podjednaku rodnost. Nešto malo veći prirod dala je sorta Fertile de Coutard ali ta razlika nije statistički opravdana u odnosu na druge dvije sorte.

$\mathrm{U}$ tablici 5 uspoređeni su rezultati istraživanja vegetativne razvijenosti i rodnosti za tri sorte uzgajane na vlastitom korijenu i podlozi Corylus colurna. Rezultati istraživanja pokazuju da su istraživane sorta na podlozi Corylus colurna postigle veću bujnost i rodnost nego uzgajane na vlastitom korijenu.

Tablica 5. Vegetativna razvijenost i rodnost sorti lijeske na vlastitom korijenu i podlozi Corylus colurna

Table 5 Vegetative growth and yield of hazelnut varieties on own root and on rootstock Corylus colurna (Miljković 1990.)

\begin{tabular}{|l|c|c|c|c|c|c|}
\hline \multirow{2}{*}{$\begin{array}{c}\text { Sorta } \\
\text { Cultivar }\end{array}$} & $\begin{array}{c}\text { Podloga } \\
\text { Rootstock }\end{array}$ & $\begin{array}{c}\text { Promjer } \\
\text { debla }(\mathrm{cm}) \\
\text { Trunk } \\
\text { diameter }\end{array}$ & $\begin{array}{c}\text { Visina } \\
\text { stabla }(\mathrm{cm}) \\
\text { Height of } \\
\text { Tree }\end{array}$ & $\begin{array}{c}\text { Širina } \\
\text { Krošnje }(\mathrm{cm}) \\
\text { Spread of } \\
\text { Crown }\end{array}$ & $\begin{array}{c}\text { Prirod } \\
\mathrm{kg} / \mathrm{stablo} \\
\text { Yield } \\
\mathrm{kg} / \text { Tree }\end{array}$ & $\begin{array}{c}\text { Prirod } \\
\mathrm{kg} / \mathrm{ha} \\
\text { Yield } \\
\mathrm{kg} / \mathrm{ha}\end{array}$ \\
\hline \multirow{2}{*}{$\begin{array}{l}\text { Istarski } \\
\text { duguljasti }\end{array}$} & $\begin{array}{c}\text { vlastiti korijen - } \\
\text { own root }\end{array}$ & 7,20 & 248 & 229 & 3,15 & 1560 \\
\cline { 2 - 7 } & C. colurna & 10,32 & 284 & 292 & 4,35 & 1740 \\
\hline \multirow{2}{*}{$\begin{array}{l}\text { Fertile de } \\
\text { Coutard }\end{array}$} & $\begin{array}{c}\text { vlastiti korijen - } \\
\text { own root }\end{array}$ & 8,66 & 298 & 233 & 3,30 & 1630 \\
\cline { 2 - 7 } C. colurna & 16,34 & 362 & 534 & 4,86 & 1944 \\
\hline \multirow{2}{*}{$\begin{array}{c}\text { Tonda } \\
\text { Romana }\end{array}$} & $\begin{array}{c}\text { vlastiti korijen - } \\
\text { own root }\end{array}$ & 8,10 & 310 & 231 & 3,15 & 1560 \\
\cline { 2 - 7 } & C. colurna & 10,07 & 320 & 248 & 4,30 & 1720 \\
\hline
\end{tabular}


U tablici 6 izneseni su rezultati istraživanja kemijskog sastava lišća istraživanih sorti na vlastitom korijenu i podlozi Corylus colurna

Tablica 6. Utjecaj podloge na kemijski sastav lišća sorata lijeski (Miljković 1990.)

Table 6 Influence of rootstock on the chemical composition of leaves of hazelnut varieties

\begin{tabular}{|c|c|c|c|c|c|c|c|c|}
\hline $\begin{array}{l}\text { Sorta na vlastitom } \\
\text { korijenui podlozi } \\
\text { Corylus colurna } \\
\text { Variety on own root } \\
\text { and rootstock } \\
\text { Corylus colurna }\end{array}$ & $\begin{array}{l}\mathrm{N} \\
\%\end{array}$ & $\begin{array}{l}\mathrm{P} \\
\%\end{array}$ & $\begin{array}{l}\mathrm{K} \\
\%\end{array}$ & $\begin{array}{l}\mathrm{Ca} \\
\%\end{array}$ & $\begin{array}{l}\mathrm{Mg} \\
\%\end{array}$ & $\begin{array}{l}\mathrm{Mn} \\
\mathrm{ppm}\end{array}$ & $\begin{array}{l}\mathrm{N}+\mathrm{P}+\mathrm{K} \\
\text { Intenzitet } \\
\text { hranidbe }\end{array}$ & $\begin{array}{c}\mathrm{Ca}+ \\
\mathrm{Mg} / \mathrm{K} \\
\text { Ravnoteža } \\
\text { katina }\end{array}$ \\
\hline $\begin{array}{l}\text { Fertile de Coutard: } \\
\text { vlastiti korijen - own root: } \\
\text { Corylus colurna: }\end{array}$ & $\begin{array}{c}2,19 \\
2,60^{*}\end{array}$ & $\begin{array}{l}0,15 \\
0,17\end{array}$ & $\begin{array}{c}0,99 \\
1,30^{*}\end{array}$ & $\begin{array}{l}1,18 \\
1,23\end{array}$ & $\begin{array}{c}0,40 \\
1,02^{*}\end{array}$ & $\begin{array}{c}0^{*} \\
652\end{array}$ & $\begin{array}{l}4,91 \\
6,32\end{array}$ & $\begin{array}{l}1,59 \\
1,73\end{array}$ \\
\hline $\begin{array}{l}\text { Tonda Romana } \\
\text { vlastiti korijen - own root: } \\
\text { Corylus colurna }\end{array}$ & $\begin{array}{c}2,28 \\
2,53^{*}\end{array}$ & $\begin{array}{l}0,15 \\
0,16\end{array}$ & $\begin{array}{c}1,02 \\
1,20^{*}\end{array}$ & $\begin{array}{l}1,21 \\
1,19\end{array}$ & $\begin{array}{c}0,20 \\
0,70^{*}\end{array}$ & $\begin{array}{c}681^{*} \\
569\end{array}$ & $\begin{array}{l}4,86 \\
5,78\end{array}$ & $\begin{array}{l}1,38 \\
1,57\end{array}$ \\
\hline $\begin{array}{l}\text { Cosford } \\
\text { vlastiti korijen - own root: } \\
\text { Corylus colurna }\end{array}$ & $\begin{array}{c}2,20 \\
2,47 *\end{array}$ & $\begin{array}{l}0,14 \\
0,15\end{array}$ & $\begin{array}{c}1,03 \\
1,31^{*}\end{array}$ & $\begin{array}{l}1,21 \\
1,24\end{array}$ & $\begin{array}{c}0,30 \\
0,80^{*}\end{array}$ & $\begin{array}{c}669^{*} \\
562\end{array}$ & $\begin{array}{l}4,88 \\
5,97\end{array}$ & $\begin{array}{l}1,46 \\
1,55\end{array}$ \\
\hline $\begin{array}{l}\text { Istarski duguljasti } \\
\text { vlastiti korijen - own root: } \\
\text { Corylus colurna }\end{array}$ & $\begin{array}{c}2,27 \\
2,52^{*}\end{array}$ & $\begin{array}{l}0,16 \\
0,17\end{array}$ & $\begin{array}{c}0,96 \\
1,19^{*}\end{array}$ & $\begin{array}{l}1,21 \\
1,24\end{array}$ & $\begin{array}{c}0,26 \\
0,70^{*}\end{array}$ & $\begin{array}{c}846^{*} \\
578\end{array}$ & $\begin{array}{l}4,86 \\
5,82\end{array}$ & $\begin{array}{l}1,53 \\
1,60\end{array}$ \\
\hline
\end{tabular}

* Razlika je signifikantna na razini $\mathrm{P}=0,05 \%$

Prema Olsenu (2001.) opskrbljenost lišća sorti lijeske na vlastitom korijenu i podlozi Corylus colurna je normalna, ali je ipak bolja opskrbljenost na podlozi Corylus colurna, pa je utvrđena statistički opravdana razlika u koncentraciji dušika, kalija i magnezija. Koncentracija fosfora i kalcija je također veća u lišću stabala na podlozi Corylus colurna nego na vlastitom korijenu, ali ta razlika nije statistički opravdana. Koncentracija mangana je veća u lišću stabala na vlastitom korijenu nego na podlozi Corylus colurna, a razlika je statistički opravdana. Prema ocjeni koju iznosi Olsen (2001.) koncentracija mangana je povišena iznad normale. U tablici 7 izneseni su rezultati istraživanja kemijskog sastava lišća, odnosno opskrbljenosti hranivima stabala s različitim intenzitetom prijevremenog opadanja plodova. 
Tablica 7. Kemijski sastav lišća, intenzitet hranidbe i ravnoteža kationa, u postotku suhe tvari, stabala lijeske s različitim intenzitetom opadanja plodova

Table 7 Chemical composition of leaves, intensity of nutrition and cation balance, as a percentage of dry matter, hazelnut trees with varying intensity of fruit dropping

\begin{tabular}{|l|c|c|c|c|c|c|c|c|}
\hline $\begin{array}{c}\text { Intenzitet opadanja } \\
\text { Dropping intensity }\end{array}$ & $\begin{array}{c}\text { Pepeo (\%) } \\
\text { Ash (\%) }\end{array}$ & $\mathrm{N}$ & $\mathrm{P}$ & $\mathrm{K}$ & $\mathrm{Ca}$ & $\mathrm{Mg}$ & $\mathrm{N}+\mathrm{P}+\mathrm{K}$ & $(\mathrm{Ca}+\mathrm{Mg}) / \mathrm{K}$ \\
\hline Veće & 7,72 & 2,34 & 0,14 & 0,60 & 1,58 & 0,21 & 3,08 & 3,00 \\
\hline Manje & 8,20 & 2,42 & 0,15 & 0,60 & 174 & 0,22 & 3,17 & 3,30 \\
\hline L. S. D. $5 \%$ & 0,47 & N. S. & N. S. & N. S. & 0,14 & N. S. & N. S. & N. S. \\
\hline
\end{tabular}

Prema ocjeni stupnja opskrbljenosti biogenim elementima prema Olsenu (2001.) lišće lijeske je normalno opskrbljeno: dušikom, fosforom, kalcijem i magnezijem, a slabo, odnosno ispod normale kalijem. Prema skali opskrbljenosti, što je iznosi Roversi (1980., 1990.) lišće lijeske je slabo opskrbljeno kalijem. Više istraživača prijevremeno jače opadanje plodova pripisuje nedostatnoj opskrbljenosti lijeske kalijem.

\section{RASPRAVA}

Ukratko se osvrćemo na pregled istraživanja bioloških i gospodarskih značajki sorti lijeske u Istri. Prva istraživanja sa sortama Istarski duguljasti, Istarski okruglasti i tipovima izdvojenim iz bogate populacije započeli su Miljković i Žužić, a rezultate rada objavili na Prvom međunarodnom kongresu o lijeski u Avellinu (1983.). Prve rezultate istraživanja u pokusnim voćnjacima sa: Istarskim duguljastim, Istarskim okruglastim i 6 stranih sorti objavili su Miljković i Prgomet (1992.) na Trećem međunarodnom kongresu o lijeski u Albi (Italija) i Miljković i Jemrić (1996.) na Četvrtom međunarodnom kongresu o lijeski u gradu Ordu (Turska). Uvođenje stranih sorti za uzgoj na vlastitom korijenu u pokusne proizvodne voćnjake, odabran je na osnovi radova Manzoa i Tamponija (1980., 1982., 1983.). Miljković (1990.) je obznanio rezultate istraživanja uzroka prijevremenog opadanja plodova u obliku izvješća Međunarodnom centru za visoke studije poljoprivrede Mediterana u Parizu, 1990. U ovom radu iznose se rezultati nastavka istraživanja, kojima se želi pridonijeti boljem poznavanju bioloških i gospodarskih osobina sorti lijeske u ekološkim uvjetima Istre. Prilog tome su i istraživanja korijenove mreže lijeske 
u crvenici na zapadnoj obali Istre (Miljković, 1976). Tu su osvrti na aktualne probleme kulture lijeske (Miljković 1984., 1959., Miljković Vrsaljko 1999., Modic i sur. 1975., 1983.). Problematikom zaštite lijeske od bolesti i štetnika u Istri bavio se I. Žužić (1986.) i Ciglar i Žužić (1983.). Rezultati istraživanja izneseni u ovom radu odnose se na uzgoj lijeske u uvjetima suhog gospodarenja. Sorte uzgajane na vlastitom korijenu više trpe od suše, jer pliće rasprostiru korijenovu mrežu od sorti cijepljenih na podlozi Corylus colurna. Nema sumnje da bi lijeska uzgajana na vlastitom korijenu i podlozi Corylus colurna bolje uspijevala i davala veće prirode uz uvjete natapanja, jer je dobro poznato da lijeska zahtijeva dovoljno vlage tijekom perioda vegetacije. Veća bujnost i rodnost na podlozi Corylus colurna posljedica je, prije svega, veće otpornosti na sušu, a time i veće prosječne dužine jednogodišnjih izbojaka, o kojima ovisi količina priroda, kao što su to utvrdili: Bauckmann (1990), Painter i Hartman (1957., 1958.). Kako u Istri postoje, općenito uzevši, vrlo povoljni ekološki uvjeti za uzgoj lijeske to bi trebalo razmotriti mogućnost natapanja i uvođenja novih tehnologija uzgoja u gustom sklopu ili uzgoja na podlogama veće bujnosti koje bolje podnose sušu.

\section{ZAKLJUČCI}

Na osnovi provedenih istraživanja mogu se izvesti sljedeći zaključci:

Do kraja 6. vegetacije sve su sorte na podlozi Corylus colurna postigle dobru vegetativnu razvijenost. Veću bujnost od ostalih sorti postigla je sorta Fertile de Coutard. Razlika je signifikantna. Podjednaku bujnost postigle su sorte: Cosford, Tonda Gentile Romana, Gunslebener, Magonca, Istarski duguljasti i Merveille de Bollwiller.

Najveći prirod u 6. vegetaciji dala je sorta Cosford (2080 kg/ha), a slijedi je sorta Fertile de Coutard (1944 kg/ha). Između ove dvije sorte utvrđena je signifikantna razlika $\mathrm{u}$ visini priroda.

Podjednak prirod imaju sorte: Istarski duguljasti (1740 kg/ha), Tonda Gentile Romana (1720 kg/ha), Magonca (1700 kg/ha) i Gunslebert (1648 $\mathrm{kg} / \mathrm{ha}$ ). Između sorti Cosford, i Fertile de Coutard s jedne strane i sorti Istarski duguljasti, Tonda Gentile Romana, Magonca i Gunslebert razlika u prirodu je statistički opravdana.

Najmanji prirod ostvarila je sorta Merveille de Bollwiller (1560 kg/ha). Razlika je signifikantna u odnosu na ostalih 6 sorti.

Sorte: Fertile de Coutard, Tonda Gentile Romana i Istarski duguljasti na vlastitom korijenu postigle su dobru vegetativnu razvijenost do kraja 6 . vegetacije. Veću bujnost od sorte Istarski duguljasti postigle su sorte Fertile de 
Coutard i Tonda Gentile Roman. Između sorata u bujnosti je utvrđena signifikantna razlika.

$\mathrm{Na}$ vlastitom korijenu uzgojene sorte: Fertile de Coutard $(1630 \mathrm{~kg} / \mathrm{ha})$, Istarski duguljasti $(1560 \mathrm{~kg} / \mathrm{ha}) \mathrm{i}$ Tonda Gentile Romana $(1560 \mathrm{~kg} / \mathrm{ha})$ postigle su u 6 . vegetaciji podjednak prirod.

Usporedbom vegetativne razvijenosti i rodnosti sorti: Fertile de Coutard, Istarski duguljasti i Tonda Gentile Romana, uzgojenih na vlastitom korijenu i na podlozi Corylus colurna proizlazi da su sorte na podlozi Corylus colurna postigle veću bujnost i rodnost nego na vlastitom korijenu.

Usporedbom opskrbljenosti lišća biogenim elementima u sorti uzgojenih na podlozi Corylus colurna i vlastitom korijenu ustanovljeno je da lišće sorti na podlozi Corylus colurna sadrži signifikantno više dušika, kalija i magnezija, a manje mangana od lišća sorti na vlastitom korijenu. Koncentracija fosfora i kalcija je također nešto veća na podlozi Corylus colurna, ali nije statistički opravdana.

Prijevremeno opadanje plodova ustanovljeno je uz nedovoljnu opskrbljenost lišća kalijem $(0,60 \%)$. Signifikantno veće opadanje plodova bilo je uz nižu koncentraciju kalcija.

\section{LITERATURA}

BAUCKMANN M., (1979.): Versuchsergebnisse aus dem Haselnussanbau. Erwerbsobstbau, 11: 224 - 245.

CIGLAR I., ŽUŽIĆ I., (1998.): Zaštita bajama i lijeske od bolesti i štetnika. Agronomski glasnik, br. 1 - 2: 119 - 125.

GERMAINE E., SARRAQUIGNE J. P., BERSCH H., HUTIN C., LEGLISE P., TAFFIN DE H. (2004.): Le noisetier., Ctifl. INRA, Bordeaux.

MANZO P., TAMPONI G., (1980.): Osservatzioni agronomiche e pomologiche su cultivar di nocciolo di doiverse provenienze. IV Conv. pomologico „Fruta secca“" Caserta: 295 - 312.

MANZO P. TAMPONI G., (1982.): Monografia di cultivar di nocciolo Istituto Sperimentale per la Frutticoltura, Roma, p 62.

MANZO P. TAMPONI G., (1983.): Osservazioni preliminari sulla fertilita di diverse cultivar di nocciolo e loro precocita di messa a frutto. Atti del Convegno Inter. sul Nocciolo, Avellino, p. 337 - 340. 
MILJKOVIĆ I., (1976.): Korijenova mreža lijeske u crvenici na zapadnoj obali Istre. Agronomski glasnik 7 - 9

MILJKOVIĆ I., (1981.): Investiciono-izvedbeni projekt za podizanje 200 ha lijeske na površinama PK Orahovica, objekt „Bukvik“, p. 3 - 190.

MILJKOVIĆ I., ŽUŽIĆ I., (1983.): Contributo allo studio della corilicoltura croata. Atti del Convegno Internazionale sul Nocciolo. Avellino, p. 141 156

MILJKOVIĆ I., (1984.): Bonitiranje zemljišta kulture voćaka. Agronomski glasnik, $6: 881-919$.

MILJKOVIĆ I., (1984.): Aktualni problemi i smjernice za uzgoj i unapređenje proizvodnje lješnjaka i bajama u našoj zemlji. Okrugli stol o aktualnim problemima proizvodnje i prerade lješnjaka i bajama. Hrvatsko voćarsko društvo, Zagreb

MILJKOVIĆ I., (1985.): Hranidba i gnojenje lijeske, Agronomski glasnik 1 - 2 : $73-89$.

MILJKOVIĆ I., (1991.): Contribution a l'etude de la croissance de la productivité et de la cause de la chute des fruites des variété de noisetier sur lers propres racines et sur porte-greffe Corylus colurna Mill. Raport sur le programme de recherches - pour Centre International de Hautes Etudes Agronomiques Méditerranéennes (CIHAM), Paris

MILJKOVIĆ I., PRGOMET Ž., (1994.): Comporttamento di otto cultivar di nocciolo in Istria (Croatia), Acta Horticulturae 351, p. 99 - 110.

MILJKOVIĆ I., JEMRIĆ T., (1996.): Genetic specificity of mineral nutrition of hazelnut trees. Proceedings of the Fourth International Symposium on Hazelnut, Ordu (Turkey), Acta Horticulturae, 445: 441 - 448.

MILJKOVIĆ I., (1998.): Sistematika roda Corylus. Pomologia Croatica 4 (1 4): 55 - 77.

MILJKOVIĆ I., VRSALJKO A., (1999.): Proteini u voću s posebnim osvrtom na lupinasto voće. Akademija medicinskih znanosti Hrvatske - Senat Odbor za dijetetiku, p. 93 - 106.

MODIC D., MANUŠEV B., HLIŠČ T., BUGARČIĆ V., MILJKOVIĆ I., KRGOVIĆ LJ., (1975.): Predlog jugoslavenskog sortimenta lješnjaka. Jug. voćarstvo br. 33 - 34: 49 - 59. 
MODIC D., Bugarčić V., Hlišč T., Manušev B., Miljković I., Krgović LJ., (1983.): Novi jugoslavenski sortiment leske. Jug. voćar. br. 63 - 64.

OLSEN J., (2011.): Nutrient management guide - hazelnut. Ore. State. Univ. Ext. Serv. Bul. EM 8786.

PAINTER J. H., HARTMAN H., (1957.): Length of fruiting twigs in relation to production and grade of filbert nuts. Oreg. State Hort. Soc. Ana. Rpt. 49th Ann. Rept. Oregon Sta. Hort. Soc., 49:193 - 199. 1957.

PAINTER J. H., HARTMAN H., (1958.): Effect of length of twigs on the fruiting performance of filbert trees. Proc. Nut. Growers of Oregon and Washington. 49 - 56.

PRGOMET Ž., (1989.): Pomološke i gospodarske osobine introduciranih sorti lijeske u Istri. Magistarski rad, Fakultet poljoprivrednih znanosti Sveučilišta u Zagrebu.

ROVERSI A., (1980.): About some relationships between soil composition and foliar leaf diagnostic. Atti 5. Coloquio Internationale sul Controlo della Nutrizione dele Piante Coltivate. Castelfranco, Veneto pp. 210 - 212

ROVERSI A., (1990.): Indagini sulle asportazione minerali del nocciolo. Fruttiocoltura 61 (11) pp. 32 - 34

ŽUŽIĆ I., (1986.): Umjerena integralna zaštita lijeske. Otokar Keršovani, Pula.

\section{Adresa autora - Author's adress:}

Prof. dr. sc. Ivo Miljković

10000 Zagreb, Čazmanska 2 
